\title{
Current Review of the Significance of Procalcitonin in the Diagnosis and Therapy of Pulmonary Infections
}

\author{
Zeqiraj $\mathbf{F}^{2}$ and Spielmanns $\mathbf{M}^{* 1,2}$ \\ ${ }^{1}$ Pulmonary Medicine, Zuercher RehaZentren Klinik Wald, Zuerich, Switzerland \\ ${ }^{2}$ Department for Pulmonary Medicine, Faculty of Health, University Witten-Herdecke, Germany
}

*Corresponding author: Spielmanns M, Department for Pulmonary Medicine, Faculty of Health, Zuercher RehaZentren Klinik

Wald, 8636 Wald-ZH, Switzerland

\section{ARTICLE INFO}

Received: 幽 October 15, 2019

Published: 幽 October 22, 2019

Citation: Zeqiraj F, Spielmanns M. Current Review of the Significance of Procalcitonin in the Diagnosis and Therapy of Pulmonary Infections. Biomed J Sci \& Tech Res 22(2)-2019. BJSTR. MS.ID.003720.

Keywords: Procalcitonin; AECOPD; CAP; Acute Bronchitis

\section{ABSTRACT}

The unnecessary prescription and unnecessarily prolonged durations of antibiotic therapy are global issues that lead to antibiotic resistance. The prevalence of these issues is particularly high in the management of acute respiratory tract infections. Procalcitonin (PCT) is a serum-biomarker and can be used to differentiate bacterial infections from other triggers. PCT is up to $80 \%$ sensitive in detecting communityacquired pneumonia caused by bacteria. PCT-guided initiation of antibiotic therapy can reduce unnecessary prescriptions significantly. PCT-guided discontinuation shortens the duration of antibiotic therapy in community-acquired pneumonia and acute exacerbated COPD. Currently there are no binding thresholds in PCT levels to universally distinguish bacterial infections and no universal cut-off levels to imply the initiation or discontinuation of antibiotic therapy exist.

Abbreviations: AECOPD: Acute Exacerbation of Chronic Obstructive Pulmonary Disease, ARTI: Acute Respiratory Tract Infections, CAP: Community-Acquired Pneumonia, DOT: Days of Antibiotic Treatment, LRTI: Lower Respiratory Tract Infections, PCT: Procalcitonin

\section{Introduction}

Antimicrobial resistance is responsible for 700,000 deaths per year worldwide, and a progressive rise is foreseen with predictions rising up to 10 million deaths globally by 2050. In addition, healthcare-associated infections (HAI) affect 4.5 million patients worldwide, prolong Length of Stay (LOS) by 16 million days, and are responsible for 37,000 deaths each year in Europe. The annual cost of antimicrobial resistance and HAI in the European Union is estimated at between 1.5 and 7 billion euros, respectively. The maximum exponents of this situation are the intensive care units, where vulnerable critically ill patients require invasive devices and receive more antibiotics [1-3]. The unnecessary prescription and prolonged durations of antibiotic therapy are global issues that lead to antibiotic resistance [4]. These two issues are particularly prevalent in the management of acute respiratory tract infections (ARTIs) $[5,6]$. Procalcitonin (PCT) is a serum-biomarker and its kinetics are linked to the phases of bacterial caused infections. PCT-serum levels rise quickly in the early phase of bacterial infection, peak within
2-4 hours and decrease with the resolution of infection. A viral etiology causes low rises of PCT-levels and therefore PCT can be used to differentiate bacterial infections from other triggers of inflammation $[7,8]$. This narrative mini-review aims to inform about the significance of decision-making guided by PCT levels in diagnosis and therapy of ART by briefly reviewing PCT-focused studies.

\section{Community-Acquired Pneumonia (CAP)}

Among all infectious diseases in the western world, pneumonia is the leading cause of deaths [9]. Clinically, CAP is associated with with productive cough, high fever and shortness of breath and is diagnosed by a proper physical examination and consolidation in the chest X-ray. Although CAP is mostly caused by bacteria, up to $20 \%$ of all CAP have viral etiologies [10]. By using a threshold of $0.1 \mathrm{ng} / \mathrm{mL}$, PCT is $80 \%$ sensitive and $51 \%$ specific in the detection of any bacterial pathogen. The levels are higher in patients with typical compared to those with atypical pneumonia [11]. Analysis of PCT levels can serve as an aide to clinical evaluation and imaging 
in uncertain cases. But there are no defined thresholds which are reliable enough to rule out pneumonia caused by bacterial infections reliably. Since CAP is associated with a very high morbidity, antibiotics should not be withheld on the basis of PCTlevels alone [12].

The main significance of PCT might lie in the cessation of antibiotic therapy in response to decreasing serum PCT-levels which occur with the resolution of an acute bacterial infection. The ProCAP - study, a prospective, single-blinded, randomized study, showed that by analyzing regular PCT-levels of an ongoing infection and following a PCT-guided algorithm, the Days of Antibiotic Treatment (DOT) were reduced to 6 days in the PCT-group compared to 13 days in the guideline-conform group with both groups having comparable outcomes [13]. The ProHOSP study showed a lower, but still significant reduction of DOT (10.7 to 7.2 days) by using a PCT-algorithm in patients with CAP [14]. PCT- guided antibiotic discontinuation did not result in increased adverse events [15] and may cause lower costs in the medical sector and could be a relevant contributor in the fight against rising antimicrobial resistance.

\section{Acute exacerbation of Chronic Obstructive Pulmonary Disease (AECOPD)}

AECOPD is characterized by a sudden worsening of prior existing cough, sputum production and dyspnea. Infectious agents trigger most of the acute exacerbations (70\%) and bacteria are the main cause, but 30-50\% of all infectious-triggered exacerbations have a viral etiology [16] COPD-patients are very likely to be prescribed antibiotics during an acute exacerbation. While some studies show that different cut-off PCT-levels indicate a bacterial etiology $[17,18]$, there are several studies concluding that PCTlevels are not significantly higher in bacteria-caused exacerbations and therefore PCT-levels may not be reliable to distinguish between bacterial and other etiologies $[19,20]$.

AECOPD is linked to a high mortality and antibiotic therapy should therefore not be delayed by PCT-levels due to the uncertainty about serum thresholds and their reliability to discriminate bacterial triggers from other causes of exacerbation. Regarding a PCT-guided initiation of antibiotic therapy in AECOPD patients, the ProResp-study showed a $50 \%$ of all antibiotic prescriptions in the emergency department [21]. But a multicenter, randomized trial with 302 patients admitted to the ICU resulted in higher 3-month mortality in the PCT-group and did not reduce the period of antibiotic exposure [22]. PCT-guided decision making concerning the initiation of antibiotic therapy in AECOPD remains therefore highly controversial. Regarding discontinuation of an antibiotic therapy, Bremmer et al. concluded that using a PCT-driven algorithm can shorten the DOT (5.3 vs. 3.0 days) and does not result in a higher 30-day readmission rate in AECOPD patients [23]. Other studies also showed similar decrease of DOT in their AECOPDsubgroup if a PCT-guided management was performed [24]. In the ProCOLD-study PCT-guided antibiotic management resulted in the decrease of antibiotic usage for up to 6 months [25]. A recent meta-analysis including 7 RCTs $(n=1287)$ regarding antibiotic use suggested that the use of PCT-guided antibiotic therapy in patients with AECOPD can effectively reduce antibiotic prescriptions and shows similar efficacy and safety for other parameters compared with standard antibiotic therapy. However, according to the review, it does not reduce antibiotic exposure duration or antibiotic use after discharge [26].

\section{Acute Bronchitis}

Acute bronchitis is a self-limiting acute respiratory infection. Cough with or without expectorations, fever and stridor are the clinical characteristics. The etiology is usually viral and antibiotic therapy is not indicated. The ProRESP-study, a RCT that enrolled 243 patients presenting to the emergency department with symptoms of Lower Respiratory Tract Infections (LRTIs), resulted in a $73 \%$ reduction of antibiotic prescriptions in the subgroup of patients with acute bronchitis by drawing PCT-levels at time of admission and following a PCT-guided algorithm which advises against prescribing antibiotics with low PCT-levels [27]. The results suggest a high potential of avoiding unnecessary prescriptions but usually PCT-assays are expensive and there are still no defined thresholds, which might lead to difficulties in interpretation. Hence, results from the hospital setting cannot be translated one-to-one to the primary care sector where most of antibiotic prescriptions for LRTIs occur (in Switzerland, but with rates likely similar worldwide) [28].

\section{Conclusion}

PCT has developed into a promising new biomarker for early detection of (systemic) bacterial infections. Procalcitonin has utility in a number of clinical scenarios in airway infections such as CAP, however, current research suggests that among these use cases, PCT levels are most useful in the setting of AECOPD patients to determine when and if antibiotics should be initiated.

\section{References}

1. European Centre for Disease Prevention and Control. Annual Epidemiological Report (2016) Health- care-associated infections acquired in intensive care units. Stockholm [Internet]. https:// ecdc. europa.eu/sites/portal/files/documents/AER-HCAI_ICU_3_0. pdf\%0Ahttps://ecdc.europa.eu/en/.

2. WHO (2014) Antimicrobial resistance. Global report on surveillance. World Heal Organ 61: 383-394.

3. WHO (2011) Report on the Burden of Endemic Health Care-Associated Infection Worldwide. WHO Library Cataloguing-in-Publication Data. http://whqlibdoc.who.int/publications/2011/9789241501507_ eng. pdf]

4. Antibiotic resistance (2018) Who.int. Retrieved 10 October 2019 from https://www.who.int/news-room/fact-sheets/detail/antibioticresistance.

5. Aabenhus R, Hansen MP, Saust LT, Bjerrum L (2017) Characterisation of antibiotic prescriptions for acute respiratory tract infections in Danish general practice: a retrospective registry based cohort study. NPJ Prim Care Respir Med 27(1): 37. 
6. Petersen I, Hayward AC (2007) SACAR surveillance subgroup. Antibacterial prescribing in primary care. J Antimicrob Chemother 60(1): 43-47.

7. Kinetics P (2019) PCT - Molecule \& Kinetics - B・R・A $H \cdot M \cdot S$ PCT (Procalcitonin). Procalcitonin.com. Retrieved 10 October 2019, from https://www.procalcitonin.com/clinical-utilities/sepsis/pct-moleculekinetics.html.

8. Procalcitonin (2019) En.wikipedia.org. Retrieved 10 October 2019, from https://en.wikipedia.org/wiki/Procalcitonin.

9. Lungeninformationsdienst.de. (2011) Häufigkeit und Verbreitung der Lungenentzündung. [online] Available: https://www. lungeninformationsdienst.de/krankheiten/lungenentzuendung/ verbreitung/index.html [Accessed 8 0ct. 2019].

10. De Roux, Andrés, Ewig S, Lode H, Torres A, et al. (2004) Viral CommunityAcquired Pneumonia in Nonimmunocompromised Adults .CHEST 125(4): 1343-1351.

11. Self WH, Balk RA, Grijalva CG, Williams DJ, Zhu Y, et al. (2017) Procalcitonin as a Marker of Etiology in Adults Hospitalized With Community-Acquired Pneumonia. Clinical infectious diseases: an official publication of the Infectious Diseases Society of America 65(2): 183190.

12. Pfister R, Kochanek M, Leygeber T, Brun-Buisson C, Cuquemelle E, et al. (2014) Procalcitonin for diagnosis of bacterial pneumonia in critically ill patients during $2009 \mathrm{H} 1 \mathrm{~N} 1$ influenza pandemic: a prospective cohort study, systematic review and individual patient data meta-analysis. Critical care (London, England) 18(2): R44.

13. Christ Crain M, Stolz D, Bingisser R, Mueller C, Leuppi J, et al. (2005) Procalcitonin guidance significantly reduces antibiotic duration in community-acquired pneumonia: the 'ProCAP' study. Critical Care 9(Suppl 1): P166.

14. Schuetz P, Christ-Crain M, Thomann R, Schoenenberger R, Henzen C, et al. (2009) Effect of Procalcitonin-Based Guidelines vs Standard Guidelines on Antibiotic Use in Lower Respiratory Tract Infections: The ProHOSP Randomized Controlled Trial. JAMA 302(10): 1059-1066.

15. Albrich, Werner \& Rassouli, Frank \& Bucher, Birgit \& Meyer, Stefan \& Thomann, et al. (2012) Effectiveness and Safety of Procalcitonin-Guided Antibiotic Therapy in Lower Respiratory Tract Infections in "Real Life": An International, Multicenter Poststudy Survey (ProREAL). Archives of internal medicine 172(9): 715-22

16. Michels G, Kochanek M (2010) Repetitorium Internistische Intensivmedizin. S. 217. Berlin, Deutschland: Springer- Verlag.

17. Chang C, Yao WZ, Chen YH, Liu ZY, Zhang XW (2006) Value of serum procalcitonin in diagnosing bacterial lower respiratory tract infections in people with exacerbation of Chronic Obstructive Pulmonary Disease. Beijing Da Xue Xue Bao Yi Xue Ban 38(4): 389-392.

\section{ISSN: 2574-1241}

DOI: 10.26717/BJSTR.2019.22.003720

Spielmanns M. Biomed J Sci \& Tech Res

This work is licensed under Creative

Commons Attribution 4.0 License

Submission Link: https://biomedres.us/submit-manuscript.php
18. Daubin C, Parienti JJ, Fradin S, Vabret A, Ramakers M, et al. (2009) Procalcitonin levels and bacterial aetiology among COPD patients admitted to the ICU with severe pneumonia: a prospective cohort study. BMC Infect Dis 9: 157

19. Chang C, Tsao H, Hu KC, Kao KC, Chen NH, et al. (2015) Procalcitonin and C-reactive protein cannot differentiate bacterial or viral infection in COPD exacerbation requiring emergency department visits. International journal of chronic obstructive pulmonary disease 10: 767774.

20. Gao D, Chen X, Wu H, Wei H, Wu J (2017) The levels of serum procalcitonin and high-sensitivity $\mathrm{C}$-reactive protein in the early diagnosis of chronic obstructive pulmonary disease during acute exacerbation. Experimental and therapeutic medicine 14(1): 193-198.

21. Cynthia L Fowler (2011) Procalcitonin for Triage of Patients with Respiratory Tract Symptoms: A Case Study in the Trial Design Process for Approval of a New Diagnostic Test for Lower Respiratory Tract Infections. Clinical Infectious Diseases 52(4): S351-S356.

22. Daubin C, Valette X, Thiollière F, Mira JP, Hazera, P, Annane D (2011) PCTrea Study Group (2018). Procalcitonin algorithm to guide initial antibiotic therapy in acute exacerbations of COPD admitted to the ICU: a randomized multicenter study. Intensive care medicine 44(4): 428-437.

23. Bremmer DN, DiSilvio BE, Hammer C, Beg M, Vishwanathan S, et al. (2018) Impact of Procalcitonin Guidance on Management of Adults Hospitalized with Chronic Obstructive Pulmonary Disease Exacerbations. J Gen Intern Med 33(5): 692-697.

24. Schuetz P, Christ-Crain M, Thomann R, Schoenenberger R, Henzen C, et al. (2009) Effect of Procalcitonin-Based Guidelines vs Standard Guidelines on Antibiotic Use in Lower Respiratory Tract Infections: The ProHOSP Randomized Controlled Trial. JAMA 302(10): 1059-1066.

25. Stolz D, Christ-Crain M, Bingisser R, Leuppi J, Miedinger D, et al. (2007) Antibiotic treatment of exacerbations of COPD: a randomized, controlled trial comparing procalcitonin-guidance with standard therapy. Chest 131(1): 9-19.

26. Li Z, Yuan X, Yu L, Wang B, Gao F, et al. (2019) Procalcitonin-guided antibiotic therapy in acute exacerbation of chronic obstructive pulmonary disease. Medicine 98(32): e16775.

27. Cynthia L Fowler (2011) Procalcitonin for Triage of Patients with Respiratory Tract Symptoms: A Case Study in the Trial Design Process for Approval of a New Diagnostic Test for Lower Respiratory Tract Infections, Clinical Infectious Diseases 52(4): S351-S356.

28. Dominik Glinz, Selene Leon Reyes, Ramon Saccilotto, Andreas F Widmer, Andreas Zeller, et al. (2017) Quality of antibiotic prescribing of Swiss primary care physicians with high prescription rates: a nationwide survey, Journal of Antimicrobial Chemotherapy 72(11): 3205-3212.

BIOMEDICAL
RESEARCHES $\quad \begin{aligned} & \text { Assets of Publishing with us } \\ & \text { - }\end{aligned}$

